\title{
Martín Fierro en la Perspectiva de un Siglo
}

Nada más ajeno al poeta José Hernández que intentar una imagen testamentaria del gaucho, pues buscó para ese anónimo que alza definitivamente como Martín Fierro, la libertad última del canto. Acaso persiguió también, dentro de una lógica interior nunca descifrable, su propia libertad. Cada una de sus voces, cada uno de sus gestos, constantemente se rehacen en el poema, y esa misma infinitud, en una misteriosa sedimentación semántica, va fundando su reescritura y rescatándola tanto de la unicidad forzada como del gramaticalismo.

Las palabras de Martín Fierro nunca son monovalentes; tocan lo carnal de la Argentina y sopla en ellas ese ánemos ligero donde el espacio interior del cantar se superpone al ensueño. Emana del poema una violenta sensación de dificultad y extrañeza de la que. participan todas sus lecturas creadoras, sensación que, en contraste, nunca alcanzan siquiera a rozar quienes aplican al poema gauchesco groseros aparatos de mensura. Si Hernández señala como deber de los cantores el ejercicio del "contrapunto", se impone desechar aproximaciones reduccionistas y sumarse interiormente al manantial sonoto que brota de la garganta de Fierro cuando se sienta en "el plan de un bajo" a revelar su historia. El silencio se vuelve, así, voz. Nos unificamos de manera viviente con el poema y vamos hacia su propio camino desde el principio al fin en un acto de simpatía y renuncia suscitado por quien canta "con toda la voz que tiene".

Nada más ajeno, asimismo, al político José Hernández, que el propósito de limpiar de culpa mediante un acto lírico a los responsables de la humillación, la miseria y la muerte del gaucho. La poética del "cantar opinando" y la exaltación de la memoria y del "jundamento" refutan con sutil conciencia crítica la evasión de los "puetas" y "dotores" que coloreaban de bucolismo o de minuciosidad costumbrista la tragedia del gauchaje. 
Hernández no idealiza rousseaunianamente al gaucho presentándolo como "el buen hijo de la naturaleza". Sus personajes matan, trampean, desertan, enfrentan la ley que los aplasta y en ningún momento surgen idealizados. Hernández afianza la impresión de veracidad mediante dos actitudes coincidentes: no diluye el significado en un sistema exterior de referencias históricas e ideológicas; evita que la fuerza del mensaje se disgregue en el paisajismo o en las notas voluptuosas. Los sucesivos relatos o argumentos recrean nítidas experiencias, que, en su conjunto, of recen un testimonio carnal del languidecimiento y la muerte del gaucho. No tienen el sabor romántico de la aventura; son acontecimientos revelados en su desnudez por distintos personajes, cada uno de los cuales muestra la coincidencia entre su expresión y sus particulares vicisitudes y sentimientos. Hernández no es un observador privilegiado, sino un ordenador relativo y casi siempre oscuro. Mediante su omisión, mucho más perceptible de la Ida, consigue una visión totalizante, sin fracturas ni líneas divisorias. A través de las distintas versiones entrecruzadas o sucesivas de una misma realidad, consigue proyectar un sentido total. El interés de Martín Fierro no surge de su amenidad como sujet, sino de una reiteración de acontecimientos revelados por voces distintas que humanizan así la experiencia. La observación es más rica que el juicio y el mundo del poema se constituye mediante recursos lingüisticos muy matizados que, pese a la insistencia en lo verificable, no excluyen el manierismo y la aprehensión casi delirante de situaciones (la llegada de Fierro a su hogar destruido, la muerte de Cruz, la soledad del Hijo Segundo frente al cadáver del Viejo Vizcacha) y así tampoco nosotros miramos el fluir del mensaje y logramos casi siempre estar en él, tan relativos y oscuros como el creador del poema.

Desde la iniciación del canto, mediante recursos ceremoniales y dramáticos, el payador incorpora al oyente a su mundo, y mediante una forma muy amplia de recursos parenéticos, reclama su participación cuando presiente un alejamiento. Por eso el lector u oyente está en el fluir mismo de la letra. Hernández poseyó esa mirada "ardua y fecunda" que Bertolt Brecht reclama a las imágenes teatrales en relación con el hombre. Si bien surge en el Martín Fierro, y muchas veces con hondísimo desgarramiento ontológico, el ciego mandato de la "suerte", del destino o del pecado original, su peso no enajena las mediatas responsabilidades históricas. Son "jefes con estancia", jueces, pulperos, comandantes y policías quienes "enriedan" esos "negocios fieros" que el gaucho llega a entender a pesar de su "inorancia". Los vencedores embellecen o volatilizan retóricamente la expoliación de los vencidos. La mala conciencia social disfraza de heroísmo o simplemente borra las huellas de sus crí- 
menes. Hernández ataca esa suette de debilidad mnemónica de la historia. Martin Fierro saca a luz las culpas y evita que tomen vías subterráneas. Hernández se esfuerza en personalizar al gaucho; quiebra su inercia dándole conciencia de su situación. Seres humanos, fuerzas sociales y no entelequias imponen esclavitud y castigo al proletariado rural.

Hernández descubre sin atenuaciones los intereses de clase que cosifican al gaucho y mira también a su extremo exilio en una trágica dimensión universal. En la primera estrofa se habla del "hombre" $(1,3)$, no del "gaucho". Lo esencialmente doloroso del Martín Fierro se alza así como alegoría y como materia contemporánea. No cabe sino constatar el fuerte sentido actual del poema en la misma medida que, transfigurados, subsisten en esta Argentina doliente de 1972, las mismas ignominias que en la Argentina de 1872, con la notable desventaja de que en ésta sólo debemos atenernos al crecimiento indetenible de la gloria del canto hernandiano sin que nada haya redimido a la "misera vieja" que en él se denuncia patéticamente. El contrapunto frente al mensaje del canto se traslada asi a las dimensiones próximas del existir y a la interpretación sin retrocesos ni fantasmagorías del país que sufrimos. Martín Fierro of rece una dificultad extrema para situarlo dentro del marco conceptual y de la Zeitgeist de su época. Se la percibe como una obra fuera de la modernidad. Al mundo urbanizado y burgués (la "barbarie" de Sarmiento), al progresismo iluminista, la básica inalterabilidad de las nociones esenciales. A la crisis de la noción religiosa de la existencia le enfrenta una vida cargada de religiosidad; a los hallazgos del saber científico marcado por los cambios del industrialismo y las conquistas sémicas, le confronta un conocer por la memoria y por la experiencia ("porque esto tiene otra llave/y el gaucho tiene su cencia"); al intelectual (el "literato" que interrumpe pedantemente el discurso del Hijo Segundo o la Bruja), propone el hombre como es in naturam; al cosmopolitismo del 80 , su nacionalismo, la mundanalidad y el brillo, destaca su huraña opacidad; al vago optimismo decimonónico la antinomia de una matcada angustia existencial.

La inteligencia oficial del 80 miró al Martín Fierro como un texto atrasado, desencajado del entorno, reaccionario y populachero. Esto o se lo dice como ocurre en la crónica del Anutrio Bibliográfico ${ }^{1}$ o se lo deja sentir con suficiente claridad en la carta de Mitre, no obstante su condescendencia paternalista.

Hernández se acerca a una Hispanoamérica bárbara, no afrancesada,

1 Hernández, José, La vuelıa de Martín Fierro. (Reseña). (En: Anuario bibliográfico de la Repuiblica Argentina. Buenos Aires, Impr. del Mercurio, 1880, pp. 270-273). 
fuertemente unida a su expresión lingüística afinada en tres siglos de cambios; escucha la voz de la gente (palabra que reitera con expresiva insistencia en el poema), se aparta del andamiaje ideológico positivista y va encontrando un principio de cohesión para su obra en la medida que prescinde de las ideas y los prejuicios de la época. No participa de ia predilección por lo más nuevo e inmediato, sobre todo si llegaba de ultramar, tan característica de la era de "orden y progreso". Margina la moda y la ideología oficiales para atender a una sabiduría inmemorial y a la sustancia humana del gauchaje. Por eso Martín Fierro toca tan vivamente lo peculiar argentino y, al mismo tiempo, esencias de orden universal y se acerca francamente a las vivencias culturales del pueblo.

Un hiato profundo se abre entre la poesía de Hernández y la de su época. Abramos un libro casi contemporáneo a El Gaucbo Martín Fierro: Hojas al viento (1871) de Carlos Guido Spano (1827-1918), aparecido un año antes que el poema de Hernández. Allí leemos, en la segunda de las composiciones, una ofrenda lírica "A Manuel C. Jouve, cuyo climax se sintetiza en estas estrofas:

Ya no resisto; el arte, el estro, el hado, Me artastran. ;Oh embriaguez noble, celeste! iA mi la lira! Y que tu mano apreste Para ornarla un laurel recién cortado.

Mis versos, de la vida en las bermejas Auroras, volarán raudos, vibrantes, Cual en busca de cármenes fragantes Del Hybla las melíficas abejas.

$Y$ ora trovando en la fortuna erguido, Ora en la tierra mísero trovando, Avanzaré cayendo y levantando, Como un león en el desierto herido. ${ }^{2}$

Si se comparan estos versos con los preludios de Hernández a la Ida y la Vueltat, cuya materia conceptual es la misma (una invocación sobre el acto lírico), se ponen en evidencia dos códigos poéticos totalmente distintos. Guido Spano utiliza el endecasílabo, tiene a Grecia como punto de referencia (el hado, Hybla, las abejas áticas). Ajusta su adjetivación a la escritura literaria ("bermejas" aurotas, versos raudos, embriaguez

"Guido y Spano, Carlos, "A Manuel C. Gouvea" (De su: Hojas al viento. En sus: Poesías rompletas. Buenos Aires, Maucci, 1911, p. 8. 
noble, celeste). Eco de ecos, a esta poesía se la siente cerca de la Grecia francesa, que será una prolongación al modernismo. Guido Spano declara en su poema que reconoce en su propia voz ". . algún suspiro acaso/ de los sagrados bosques del Parnaso"s y libera su canto en el arrebato de la inspiración. El payador de Hernández siente, en cambio, que la lengua se le añuda y se le turba la vista, invoca a los dioses del cielo o a su Dios ("Pido a mi Dios que me asista/ en esta ocasión tan ruda"). Ante una misma circunstancia y sentimientos poéticos se levantan voces muy distintas en una separación que marca, por un lado, el acercamiento al modelo culto europeo y contemporáneo, y por el otro, la utilización estética de una poesía popular y americana. El gusto evasionista de los sectores cultos porteños presionaba el mensaje, aunque éste se aplicara a la temática gauchesca. El Lázaro (1869) de Ricardo Gutiérrez, sólo tres años anterior a $E l$ gaucho Martín Fierro, se aproxima, en cuanto alegato, al poema, pero se aparta tajantemente de él por su sensiblería byroniana, por su desubicación estetizante que lo lleva a levantar castillos en las márgenes del Paraná y a imaginar al gaucho combatiendo contra monarcas y señores feudales, cándida coartada para soslayar su crudo e inmediato drama social.

Martin Fierro no es un quieto objeto semántico. Mediante episodios o significados permutables, Hernández evita que la responsabilidad histórica se escape por el atajo verbal. Saca crudamente de la penumbra los hechos; se hacen negocios y "carriles" mientras se le "chupa la sangre" a los soldados; la tropa trabaja las estancias de los jefes; un comandante le roba la mujer a Cruz y otro le roba el caballo (obvio símbolo de poder y de orgullo viril) a Fierro; los jueces se complican en el despojamiento de los hijos de Fierro y de Picardía (el hijo de Cruz), condenan y roban a los huérfanos y "arreglan" a los delincuentes; pulpero, gringos y protegidos suman como factores de subordinación y explotación. Uno a uno aparecen los eslabones de la "cadena" opresiva. Y puesto que a los sectores humanos que arrastran situaciones de sometimiento acaba por parecerles espontánea e inmutable la situación que padecen, Hernández sacude esa sensación paralizadora. En contraste nítido muestra que hubo un antes (al que idealiza en el illo tempore de la $I d a$ ) y que, en consecuencia, puede haber también un después para esos que llama doloridamente "hijos de la miseria". Sustrae así bruscamente a la poesía del dominio de lo grato, margina el código estético-literario de su época y forja esa extraña creación que se enriquece en el seno de situaciones históricas diversas y que posee una inabarcable manifestación de paralelismos simbólicos.

\footnotetext{
3 Op. cit, p. 7.
} 
Martin Fierro conjuga la mutabilidad con una frescura que no se fija en la anécdota y en la que, ateniéndonos a una sagaz observación de Miroslav Cervenka, "los principios de la construcción de la obra alcanzan la validez de principios de la construcción del destino humano". ${ }^{4}$ Martín Fierro se constituye, salvo en los extensos pasajes narrativos de la Vuelta, como un espectáculo. Fierro y Cruz cantan sucesivamente frente a un auditorio como lo harán después el Hijo Mayor, el Hijo Segundo y Picardía. Hernández devuelve así a la poesía su originario carácter colectivo. Martín Fierro es constantemente acto y presencia. Las experiencias de Fierro, Cruz, sus hijos, Vizcacha, el Nato, Barullo, la Bruja y otros seres del Martín Fierro, se van entramando para traducir una forma de vida. Todas ellas pueden ser cotejadas sin provocar sensación de incongruencia. Hernández no se deja cautivar por lo biográfico y atiende a la función que cada personaje cumple en el conjunto.

Más que sensaciones placenteras Martín Fierro suscita una oscura incomodidad, tal vez análoga a la que "añuda" Ia lengua del cantor cuando inicia su historia. Nos exige escuchar y hablar; nos provoca al contrapunto y no se puede percibir, en ningún momento, sobre el fondo angosto de una clausura lingüistica. La victoria de Hernández es la de sus personajes que hablan sin restricciones desde el centro mismo de su agonía. Lo hacen en una lengua espontánea, no diluida por la formulación poética.

La proto-imagen de Fierro es la del cantor. Irrumpe cantando y define claramente los motivos de su contrapunto. Busca, como el ave, consuelo para su "pena estraordinaria", aunque no sea éste un desahogo intimista sino testimonio de un padecer generalizado ("pues son mis dichas desdichas/la de todos mis hermanos"); canta también por fatalidad existencial, ya que "dende el vientre de su madre" recibió un don corroborado por el "agua del bautismo", y canta también por desafío viril, por infundir solidaridad en sus hermanos. Le asiste la seguridad de que sus cantos "han de durar" y de que el cantar labra su gloria. Y así, cuando el gaucho que se pasaba noches enteras payando en las pulperías se convierte en matrero, hay algo en esa metancia que no lo abandona: el don verbal, la fuerza para reflejar desde el interior mismo de su exilio el dolor de toda su raza. ${ }^{5}$

4 "La obra literaria como símbolo" En: Lingü̈stica formal y crítica literaria, Comunicación, 3, Madrid, Alberto Corazón, ed., 1970, p. 42.

${ }_{5}$ Al subrayar la abundante materia político-social de Martín Fierro, Bella Rabinovich observa que en él encontramos "una sensibilidad étnica hasta entonces desconocida o cuando menos ignorada y desdeñada por estadistas, gobernantes y sociólogos, pero no por ello menos ponderable, menos rica en matices insospechados por su 
Martín Fierro nos enfrenta a una Argentina cuya complejidad y cuyo ímpetu se religan con los significados explícitos o latentes del poema. Las anécdotas ocultan lo menos ostensible de su mensaje; una inteligibilidad totalizadora puede acabar por sustituirlo. La historia de Fierro, con ser la parte fundamental del cantar gauchesco, es sólo el centro de una constelación cuyos componentes, aún los más escondidos, se revitalizan entre sí y suscitan un desplazamiento imaginativo hacia el contexto. La obra se abre siempre a varios niveles de lectura: el relato del Hijo Mayor puede, por ejemplo, mirarse como último grado del exilio y asociarse a otras categorías sobre la cárcel (las de Calderón o de Dante por ejemplo), puede reducirse al testimonio escrito de una experiencia dolorosa o puede ejemplificar una de las tantas formas represivas utilizadas contra el gaucho. Hernández constantemente sugiere el mito, lo universal y, a la vez, se adhiere a la realidad del gaucho. La imaginación (hacia adelante) y la memoria (hacia atrás), trasladan constantemente la atención hacia un centro único; la voz ata significados y significantes de una manera física, a veces ostensible. Sorprende la minuciosidad con que Hernández rehuye los motivos topológicos ajenos al ámbito físico y espiritual del gaucho. Esto crea una sensación de mundo clausurado y extraño, la cual, por la precisión con que está urdido, sugiere una lejanía como la de $E l$ proceso o de $E l$ extranjero.

El doble movimiento de clausura y de polisemia se vincula al hermetismo del texto, a su secreto. Toda una línea de significación va perfilándose vigorosa o tenue a través del poema: espera de lo anhelado o temido, amenazas del desierto, el fortín, la peste, temor al enemigo blanco o indio, sorpresas, vacilaciones. El grupo social primitivo y subyugado reflejado en Martín Fierro cifra su esperanza última en el canto porque alberga la memoria y la redención. El secreto de la promesa final revierte sobre todas las dimensiones del poema y el leve folleto se convierte, a través de la experiencia, en el libro. Entonces los personajes, portadores y depositarios de significados, integran un cortejo semántico, ni ilusorio ni retórico, cuya riqueza se acentúa por la conjugación dramática que combina todo un sistema de relaciones agónicas. Cabe así atenuar el significado excesivo que suele concederse a algunos momentos del poema, pues según observa Leo Hickey, en literatura, por una intrínseca debilidad del lenguaje, lo singular, ya sea una persona, una situación o un acontecimiento, sólo resulta interesante "en la medida que envuelve o sugiere algo de más amplia envergadura o significación, a que tiene un sentido general,

cantidad y sutileza". ("La moral y la religión en Martín Fierro"; en Boletin del Instituto de Sociologia, Facultad de Filosofía y Letras, Universidad de Buenos Aires, 1943, n. 2, p. 125). 
universal o abstracto". ${ }^{6}$ Martin Fierro funda su universalismo no en la sustracción de lo inmediato sino en su dramático reconocimiento: "esto es pura realidá"; "soy gaucho y entiéndalo/ como mi lengua lo esplica".

En la primera parte del poema, Martín Fierro y Cruz, los dos gauchos que cantan, y quienes oyen sus confidencias, se vinculan a un orden lingüístico que no deja penetrar materiales propios de la escritura, y esa misma delimitación corresponde interiormente a la violencia de la leva del fortín y de la persecución; en la Vuelta, Hernández introduce cierta epistemología o manera de interpretar una realidad que aparece ahora percibida por otro y desde afuera. Refuerza también la estructuración novelística, traza nuevas líneas de escritura, diversifica contenidos, todo lo cual armoniza, hasta el momento de la payada con el Moreno, con la idea de retorno. Quien comienza a cantar en la Vuelta ya no es el matrero insurrecto $y$ sufrido que rompe la guitarra antes de huir al desierto, sino un hombre que se siente.vencido, "aindiado" y "viejo" y que declara que busca procurarse trabajo. La colectividad que lo hizo su victima ha sepultado ya sus delitos con lo cual lo integra totalmente con la nada. Entonces la presencia de otro cantor lleva a Fierro al sitio de su verdadero heroísmo. Canta en "cosas de jundamento" y logra una victoria, victoria oral y espiritual, y ahora sí él y su raza se sobreponen a quienes los avasallaron. Por eso cuando se diseminan hacia los cuatro vientos, sus pasos cubren la tierra inmemorial que no los olvida. Ya en ese instante Hernández es solamente un discreto conocedor del "secreto prometido". Pero nada más. Su voz ya no puede superponerse a una libertad asumida por el poema. Sólo imaginativamente, desde el agitado mundo de quien is enfrentan a Martin Fierro en contrapunto, éste procura su origen, su dolor, su sangre.

Martin Fierro triunfa en el mismo terreno en el que Santos $V t^{\text {"ga }}$ a cayó vencido: el contrapunto. En su elègía a "A Santos Vega", Bartolomé Mitre incluyó una llamada aclaratoria al final de la estrofa sobre su muerte y allí sintetizó las noticias generalizadas a principios del siglo xIx sobre el legendario payador: "Histórico. Santos Vega murió de dolor por haber sido vencido por un joven, en canto que los gauchos llaman de contrapunto: cuando la inspiración del improvisador faltó a su menle, su vida se apagó. La tradición popular dice que aquel cantor desconocido era diavlo (sic), pues sólo él podía haber vencido a Santos Vega". ${ }^{7}$

Hernández asocia al Moreno con el diablo, de manera que el triunfo de Martín Fierro asume el significado de una reparación en el plano de lo

6 Hickey, Leo "El valor de la alusión en la literatura". (En: Revista de Occidente, Madrid, no 88, julio 1970, p. 57).

7 En: Rimas (Buenos Aires: Imprenta de Mayo 1854) p. 135. 
sagrado. Sabe el Moreno lo que su fracaso significa: "es muy larga y muy triste/la noche de la redota". Martín Fierro vence con la palabra y en la palabra. Aunque casi siempre haya sido leída literalmente, la derrota del Moreno fue escrita simbólicamente. La primera imagen de Fiero en el poema es la del cantor, que refiere sus desdichas, la imagen última es la de un payador que canta "en cosas de jundamento". Hay una gradación de lo subjetivo, acuñado en un registro épico-lírico, a lo impersonal y metafísico: es la sensación de pesadumbre propia de quien "con el cantar se consuela", a la trascendente seguridad intima; de lo romántico a lo estoico. Martín Fierro se erige como triunfador en la agonía del contrapunto asumido como deber ("encontrándose dos juntos/ es deber de los cantores/ el cantar de contrapunto". Puesto del lado no confortable y peligroso de la palabra, alcanza una imprevisible victoria. La voz surge así más poderosa que la sangre.

En el preludio de la Ida Martín Fierro exhibe sus vacilaciones, muestra su incomodidad para encontrar las correspondencias verbales a tantas situaciones propias de la existencia y del sentir del gaucho intraducibles en la escritura de los letrados. Poco a poco se va afirmando, arrasa con significaciones sedimentadas, y cuando parecen haberse agotado sus posibilidades expresivas surge, como escena-testigo controlando todas las dimensiones del poema, la payada con el Moreno. Dentro de un clima intemporal, el dinamismo de la payada es exclusivamente mental; el juego de preguntas y respuestas crea una sensación de simultaneidad y la índole de los temas establece una permanencia despojada de duración. Se borran a esa altura los particularismos lingüísticos y los temas responden a un sondeo metafísico del mundo y la existencia en total divorcio con la cosmovisión positivista-determinista de la inteligencia de su época. Este es otro aspecto en el que Hernández se separa de la modernidad y atiende a solicitaciones intemporales. Sus contemporáneos ejercían una forma de actitud de vanguardia muy típica de los países periféricos y exhibian una escritura de réplica y hasta un peculiar nacionalismo literario que consistía en reproducir, sin mayores variantes, las modas vigentes en Francia inclinadas a lo "folk" e individualizado. Hernández se aparta siempre del americanismo costumbrista y del abuso de color local y, en el momento de la payada entre Fierro y el Moreno, se atiene estrictamente a una forma de expresión popular tan arraigada y tan fijada en una ceremonia como es el cantar de contrapunto.

El poema de Hernández requiere cierto suspenso del juicio para que la palabra asediada deje brotar sus significados. Aunque casi todos ellos se unan al tema fundamental de la agonía del gaucho, el cantar se estructura como un trama de oposiciones dinámicas y se enriquece con una intensa 
variedad de motivos, cada uno de los cuales modula variantes de escritura. La significación ostensible del Martin Fierro como alegato y alegoría del gaucho no puede precipitarnos a empobrecer unívocamente su contenido. Un movimiento de ese tipo equivale a estabilizar el mensaje de Martín Fierro, a recluirlo en un osatio académico, a condenatlo, en función de reescrituras que tapan su voz, a un lujoso destierro infinitamente más cruel que el de la frontera.

Lo que Martín Fierro necesariamente sigue reclamando no es su disolución en otra escritura, por deslumbrante y creadora que ésta puede ser. Se trataria de una disfunción semántica, de un trueque. Precisamente al poner en oposición los núcleos radicales de la obra, de alguna manera se logra superar las instancias subjetivas sin eliminarlas hacia sí mismo, cobra una corporeidad dramática y descubre todo lo que hay de tortura y extraña desesperación, en esos seres sobre los que el sufrimiento cae con insistencia. Medimos entonces hasta qué alejamiento puede llevarnos una lectura que nos deje en paz promoviendo al "pobre Martín Fierro" como Hernández lo llamaba, a personaje estatuario o a criatura maravillosamente fuera de la vida.

Martin Fierro se constituye como poesía y como realidad, como "sonido" y como "intención", con lo cual simultáneamente conforma y transgrede su propio espacio expresivo. Cuando se supera la inevitable inclinación a tapar el texto, y se deja que éste hable, lo que, por lo menos al comienzo de este ejercicio de ascesis, importa una restricción, se convierte en acercamiento a lo que Martín Fierro posee de singular; su asombro cósmico, su tragedia, su exasperado desacuerdo con la cultura que lo aplasta.

Martín Fierro remueve profundamente. Unamuno confesó esa sensación de sacudimiento, de asombro y de extrañeza frente al poema. Las respuestas abarcan una gama muy compleja que va de la percepción de lo heroico (Lugones) a la de lo elegíaco ("poemas de lágrimas" lo llamó Saldías), y esto para mencionar solamente puntos extremos: una lectura creativa siempre actualiza los significados prohibidos del poema. $\mathrm{Y}$ cuando, desde el presente, el poema libera su fuerza trágica, es cuando al mismo tiempo recobra el espacio y el tiempo que vieron la muerte del gaucho. Después de un pasaje casi ilusorio donde se insinúa la reconciliación con la historia, Martín Fierro y su prole se dispersan para siempre. En esa imagen última, cargada de grave silencio, puede descubrirse la dimensión donde Martín Fierro avanza salvado.

La voz derrota a la escritura y triunfa fervientemente sola, salvaje, imprecatoria, blasfema, en presencia nuestra, abriéndose al contrapunto a partir del "Aquí me pongo a cantar", que a la vez inicia y cierra el 
poema. Queda el libro "infinito", pero esa sustracción semántica convierte a Martín Fierro en creatura supra-histórica y proyecta una dimensión que constituye a la obta. Se sale asi del mundo delimitado de los hechos para abarcar el mundo removedor de los significados, válidos éstos para 1872 como para 1972, y para siempre. Entonces aparece la obra en presencia, se corporiza, alcanza a personalizar al gaucho y a darle definitivamente un morada psicológica, con lo cual cumple Hernández la misteriosa misión del poeta, tan insustituíblemente percibida por Shakespeare: "... and gives to air nothing/ A local habitation and a name" (Midsummer. ., 1, V, 14).

Cuando Martín Fierro concluye sus confidencias, en el canto XIII de la $I d d$, lo hace diciendo: "en fin, amigo, yo salgo/de estas pelegrinaciones". Sigue después un silencio, señalado por seis líneas de puntos suspensivos equivalentes a una sextina; luego es Hernández quien cierra esta parte del poema. En La Vuelta, al final del canto XXXII, también en un momento bien singularizado, cuando Martín Fierro concluye los consejos a sus hijos, les dice: "Estas cosas y otras muchas/medité en mis soledades". Pelegrinaciones, soledades: ambas palabras aparecen en instantes definitivos: "pelegtinaciones" es la última que pronuncia Fierro antes de emprender su exilio a las toldetías indigenas; soledades es la que sintetiza su existencia cuando concluye de hablar con su prole. Surgen así como claves tanto de la estructura como del significado del poema. Acaso podría llamárselas también "palabras-abismo", según la denominación aplicada por Jean-Pierre Richard para algunas expresiones de Gerard de Nerval cargadas de profundidad semántica. ${ }^{8}$ La andanza, la aventura, sean impuestas o voluntarias (pelegrinaciones), el destierro y el asilamiento de la sociedad y la familia (soledades), se proyectan hacia lo histórico y hacia lo mítico, hacia lo individual y hacia lo genérico. Peregrinación y soledad marcan el destino de Fierro y de los gauchos, soledad y peregrinación más genéricamente, sintetizan también el destino del hombre. El mundo de Martin Fierro puede ordenarse en torno a este doble cantro de significaciones cargado de atracción magnífica y dar así un alcance nuevo a muchas ideas y matices.

Resulta imposible establecer si Hernández procedió reflexivamente o no al ubicar con tanta precisión esas palabras-testigo. Vale sí comprobar cómo ellas descubren una actitud. Había sufrido carnalmente al país ese varón casi desconocido por sus contemporáneos más ilustres que, en el cuarto de un hotel, fue dando forma definitivamente al Martin Fierro; también él buscaba consuelo en el cantar y también dejaba un mensaje

8 "Geographie magique de Nerval", en Poésie et Profondeur (París: Ed'. Du Seuil 1955), p. 76 . 
doliente en la voz de sus personajes. Resulta sugestivo recordar que, por los mismos años, Dostoyevski confesaba sobre Los endemoniados: "Lo que escribo es tendencioso. Quiero expresarme con fuego". Superando fronteras, la actitud de Hernández parece la misma. Hundidas en su tierra las obras maestras buscan al hombre de todos los tiempos y comarcas y descubren significados muy esenciales como los que surgen de las pelegrinaciones y soledades de nuestro cantar.

Martin Fierro constituye una transgresión contra el orden intelectual del 80. Sus personajes o conflictos y las situaciones que afrontan se integran patéticamente en una notoria disyunción con los valores del grupo social que los somete. El poema combina todo un sistema expresivo que según sea el tipo de lectura, deja ver dimensiones diferentes e igualmente aceptables. Ellas se extienden desde el testimonio social hasta un orden mítico que of rece metamorfosis originales de situaciones arquetípicas. Su coherencia surge de la claridad y aun de la clarividencia con que Hernández fusiona los motivos y los seres del poema con una formulación expresiva coherente.

En numerosos prólogos y notas, a partir de la carta a José Zoilo Miguens que precede a la $I d d$, Hernández enuncia sus ideas literarias. Pero aunque no poseyésemos tales declaraciones nos quedaría la poética implícita en el poema, basada en un equilibrio entre el jundamento y el sentimiento, la voz y la intención, el testimonio y la profecía. Hernández consigue una escritura acorde con sus ideas sobre lo poético. De esa escritura debe partirse, pues toda crítica en cuanto metalenguaje es subsiguiente a la obra-objeto. De modo que reducir a Martín Fierro a una especie de revelador sintomático del entorno y regularlo según las particulares orientaciones o prejuicios sólo lleva a apagar la rebelión de Hernández. El discurso que instrumentaliza a Martín Fierro hipostasia una variable aceptada dogmáticamente y le atribuye carácter final. Otro camino de desacuerdo es ordenar inventarios, reducciones fáciles, clasificaciones exteriores o gramaticalizaciones.

Pocas, muy pocas veces suscita Martin Fierro esa sensación de redundancia que surge de las obras de sus contemporáneos. El poema no nace ex-nibilo, pero la importancia de la divergencia de Hernández radica en que éste no procede por réplica frente al modelo prestigioso ni se pliega al tono intelectual del 70 marcado por la decadencia romántica y por los comienzos del positivismo.

Martín Fierro se inscribe en un proyecto original que estéticamente armoniza con la actitud independiente y con la rebeldía política de Hernández. Hernández utiliza con seguridad un afinadísimo instrumento lingüistico originado en el material oral más que en el escrito, pero sería 
falsear su obra el verla como un bricolage de residuos folklóricos. Martín Fierro se ubica en el plano de una inteligencia y de una escritura cohesionadas con una complejísima actitud frente al mundo que, sin incomodidad, podemos llamar argentina y donde se combinan la independencia y la compadrada, la amistad y la indolencia, el apego a la tierra puro horizonte y el sentido de soledad... En fin: ninguna enumeración podría agotar el sentido y el sentimiento que el, poema proyecta. En sus zonas de conflicto la obra de Hernández no es coextensiva con los patrones literarios ni con el código histórico-social de su época. De haber aceptado ese código y de haberse replegado a la escritura del 80 , su mensaje resultaría sofocado y la restricción que pesaba sobre el gaucho hubiese abarcado también a la palabra.

Hernández asume desde el canto la conciencia posible del grupo cuya opresión denuncia. Salva decididamente la fuerza del verbo que no ha podido ser avasallada. Ese es su núcleo de afirmación y de rebeldía. La palabra va desocultando una virtualidad inalienable. Ofrece una constelación en la que siempre unto es todos y en la que nadie se constituye en doble de otro, pero, además, alza su voz hacia una región donde, sin excluir siquiera lo que el poema contiene de voluntariamente elusivo a enigmático, se cuestionan las esencias del mundo y del existir. En esa dimensión se sitúa la payada con el Moreno. El contrapunto culmina con una victoria de Fierro que es a la vez una renuncia y un anuncio. Se siente a esa altura lo necesario que somos al poema, la misteriosa participación de todos - palabra tan significativa en Hernández- en la construcción del debate. Martín Fierro arroja un clamor histórico y vital, señala como deber "el cantar de contrapunto". El poema no habla a quienes lo reciben mansamente ni a quienes lo reemplazan con pedantería de "literatos". Su voz inquieta e inquietante se unifica con las voces que enriedan al texto, que se comunican con su sangre.

Antonio Pagés Larraya

Universidad de Buenos Aires 
